\title{
Insecticidal effects of Parthenium hysterophorus and Moringa oleifera leaf extracts on digestibility indices and survival of Spodoptera litura (Lepidoptera: Noctuidae)
}

\author{
Muhammad Irfan Ullah'1*, Sana Majeed1', Muhammad Arshad1', Sajjad Ali², Naunain Mehmood³, Nimra Altaf', \\ Asad Abdullah¹, Muhammad Luqman', Umar Farooq ${ }^{5}$, Muhammad Afzal ${ }^{1}$ \\ ${ }^{1}$ Department of Entomology, University of Sargodha, 40100, Sargodha, Pakistan \\ ${ }^{2}$ Department of Entomology, The Islamia University of Bahawalpur, 63100 Bahawalpur Pakistan \\ ${ }^{3}$ Department of Zoology, University of Sargodha, 40100, Sargodha, Pakistan \\ ${ }^{4}$ Department of Agricultural Extension, University of Sargodha, 40100, Sargodha, Pakistan \\ ${ }^{5}$ Department of Food Science and Technology, MNS-University of Agriculture, Multan, Pakistan
}

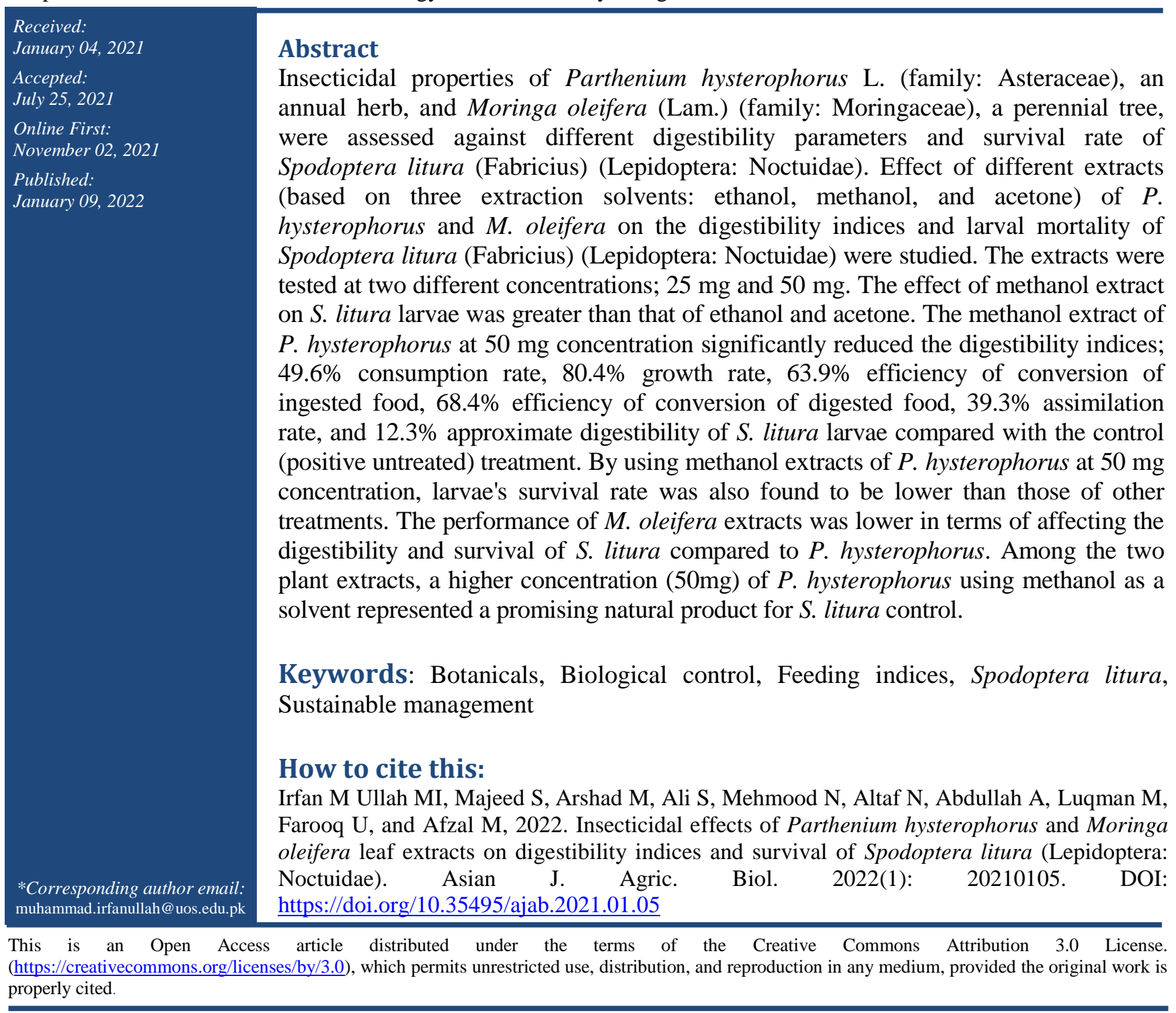




\section{Introduction}

During the past few decades, the indiscriminate and excessive use of synthetic insecticides has led to resistance development in insect pests and the accumulation of toxic residues in the environment (Isman, 2006). Thus, environmentally safer alternate compounds are urgently needed, as endorsed by national and international legislation (Dougoud et al., 2019). The search for effective pesticides has resulted in a significant market opportunity for alternative products (Isman et al., 2011). Botanical pesticides are good alternatives to synthetic insecticides in integrated pest management (Nerio et al., 2010; Pavela and Benelli, 2016). Their multiple modes of action reduce both resistance development in insects and the risk to non-target organisms because of their rapid dissipation in the environment (Rajendran and Sriranjini, 2008).

Parthenium hysterophorus L. (family: Asteraceae) is a widely spread weed, commonly known as carrot weed (chatak chandani and gajar ghas in local vernacular) (Kumar et al., 2012). It has been reported to possess insect repellent, antioxidant, antibacterial, and antifungal properties (Gören et al., 1996; Bandonien et al., 2000). Because of its biological activities, $P$. hysterophorus was successfully used to control the Indian strain of mosquito, Aedes aegypti (Culicidae: Diptera) (Kumar et al., 2012). Lectins present in the $P$. hysterophorus affect the nutritional balance and retard the growth and development of Aedes aegypti larvae (Coelho et al., 2009). Parthenin, an active ingredient in $P$. hysterophorus, possesses a strong insecticidal property and has been reported to manage red cotton stainer (Dysdercus koenigii F.) effectively, red flour beetle (Tribolium castaneum Herbst.), potato tuber moth (Phthorimaea operculella (Zell)) and pulse beetle (Callosobruchus chinensis L.) (Sharma and Joshi, 1977). Moringa oleifera (Lam.) is a widely spread perennial tree, which belongs to the Moringaceae family (Anwar et al., 2007). Seeds of $M$. oleifera are a rich source of bioactive proteins, such as lectins, with various biological activities (de Lima Santos et al., 2014). A lectin isolated from $M$. oleifera, named $\mathrm{cMoL}$ (coagulant $M$. oleifera lectin), possesses insecticidal activity against the Mediterranean flour moth (Anagasta kuehniella Zeller (Lepidoptera; Pyralidae)) (Santos et al., 2009). Lectin interferes with the molting process in insects, such as Zonocerus variegatus (Lepidoptera: Pyralidae) and Tribolium castaneum (Coleoptera: Tenebrionidae) (de Oliveira et al., 2011; Anita et al., 2012), causing growth disruption. Three lectins, SLL-1, SLL-2, and SLL-3, present in leaves of $M$. oliefera, are reported to have high antibacterial activity (Khatun et al., 2009).

Insecticidal activity of plant extracts may vary according to plant part, solvent, extraction methods and insect species. The antifeedant activity of these plant extracts could be different using different type of solvents. Baskar et al. $(2009,2010)$ showed the insecticidal properties of different plant extracts using acetone as a solvent against lepdopterous insect pest. The differences in insecticidal efficacy of plant extracts are more likely due to the extraction efficiency of the different solvents however hydrophobic compounds with bioactivity are reported to be more efficiently extracted by methanol than water (Mkindi et al., 2017; Dougoud et al., 2019). Similarly, Feng et al. (2012) reported strong antifeedant activity of thirty Chinese medicinal plants using ethanol as a solvent against Spodoptera exigua (Lepidoptera: Noctuidae).

Spodoptera litura Fabricius (Lepidoptera: Noctuidae), a polyphagous insect pest, attacks various crops in Pakistan (Ahmad et al., 2007). It is distributed worldwide, especially in tropical and temperate regions, including Asia, Australasia, Christmas Island, Cocos Island, Andaman, and Nicobar Islands (EPPO, 2014; Monobrullah and Shankar, 2008; Liu et al., 2018). It can cause 26 to $100 \%$ economic losses, depending upon the crop stage and infestation level (Khan et al., 2018). In Pakistan, S. litura is considered a devastating leaffeeding insect pest ( Khan et al., 2011), which causes heavy losses to various cultivated crops, ornamentals, vegetables, and fruits (Ahmad et al., 2013). So, there is a dire need for sustainable, environment-friendly control measures for this pest. The current study aimed at exploring the effectiveness of $M$. oleifera and $P$. hysterophorus against the gregarious plant pest, $S$. litura to determine their insecticidal effect. Leaf extracts of $M$. oleifera and $P$. hysterophorus prepared in different extraction solvents were used to determine their effect on the digestibility and survival of S. litura.

\section{Material and Methods}

The experiment was conducted in the Department of Entomology at the College of Agriculture, and 
Department of Chemistry, University of Sargodha, Pakistan. Insect culture and treatments are described below;

\section{Insect culture}

Egg batches of $S$. litura were collected from soybean (Glycine max (L.) Merr.) field near the University. Eggs were kept in clean Petri plates under controlled conditions $\left(26 \pm 2^{\circ} \mathrm{C}\right.$ temperature, and $\left.64 \pm 5 \% \mathrm{RH}\right)$. Newly hatched larvae were raised on an artificial diet (Sorour et al., 2011). Pupae were separated from Petri plates and kept in clean plastic jars $(120 \mathrm{~mm} \times 116 \mathrm{~mm} \times 95 \mathrm{~mm})$. On emergence, the adults were raised on $10 \%$ sugar solution. Cotton wool strips ( $1 \mathrm{~cm}$ wide, $5-10 \mathrm{~cm}$ long) were placed in plastic jars to facilitate oviposition. The $\mathrm{F}_{3}$ generation of $S$. litura was used in further experiments.

\section{Plant extract preparation}

Fresh leaves of $P$. hysterophorus and $M$. oleifera were collected from the research area $\left(32^{\circ} 07^{\prime} 49.3^{\prime \prime N}\right.$ $\left.72^{\circ} 41^{\prime} 07.4^{\prime \prime E}\right)$ near the University. The leaves were washed with distilled water to remove dust and contaminants. Leaves were air-dried for 48 hours, followed by oven drying at $50^{\circ} \mathrm{C}$ for $24 \mathrm{~h}$. Dried leaves were ground to a fine powder in an electrical grinder (Moulinex, France). Three extraction solvents (acetone, ethanol, and methanol) were used individually to prepare plant extracts. A 10-gram powder sample of each plant material was mixed in $100 \mathrm{ml}$ of each solvent. The solution was placed on an orbital shaker (OS-752 Pallscientific, Indonesia) for $12 \mathrm{~h}$ for thorough mixing. The solution was then filtered with a muslin cloth and Whatman No. 1 filter paper. After filtration, residues were mixed with 100 $\mathrm{ml}$ solvent, and the shaking procedure was repeated. The solution was kept in a rotary vacuum evaporator (BEV-1001V, Henan, China) to evaporate the solvent. After drying, extracts were stored in a refrigerator at $4^{\circ} \mathrm{C}$ temperature for further use.

\section{Efficacy of plant extracts against Spodoptera litura larvae}

The plant extracts of $P$. hysterophorus and $M$. oliefera were tested at two concentrations $(25 \mathrm{mg}$ and $50 \mathrm{mg}$ ) against $S$. litura larvae to determine their effect on digestibility and survival of the insect. Almost similar sizes of $3^{\text {rd }}$ and $4^{\text {th }}$ larval instars were tested for each concentration of plant extracts. Before starting the experiment, healthy larvae were selected and starved for $24 \mathrm{~h}$. Leaves of soybean were collected from the field and washed with distilled water to remove dust and contaminants. The leaves were dipped for 10 seconds in each solution and dried for $10 \mathrm{~min}$ at room temperature. Treated leaves were kept in Petri plates, and a single larva was released in each plate.

\section{Treatment layout and data recording}

Treatments, $P$. hysterophorus $25 \mathrm{mg}, P$. hysterophorus $50 \mathrm{mg}$, M. oliefera $25 \mathrm{mg}$, M. oliefera $50 \mathrm{mg}$, control (+ve) and (-ve), were arranged in a completely randomized design (CRD). Untreated larvae were considered control (+ve), and the respective solvent was applied in the control treatment (-ve). Each treatment was replicated five times, and 5 larvae were tested in each replication, totaling 25 larvae/treatment. Data on larval length and weight, the weight of leaves before and after $24 \mathrm{~h}$ of feeding, and feces weight were recorded. A daily account of the survival rate of larvae was also kept. The digestibility indices were calculated using the following formulae (Waldbauer, 1968)

\section{Growth rate (GR)}

The growth rate was expressed as the digested material available to the insect during the experimental period.

$$
G R=\frac{\Delta B}{B I \times T}
$$

\section{Consumption rate (CR)}

$$
C R=\frac{I}{B \times T}
$$

\section{The efficiency of conversion of digested food (ECD)

$$
E C D=\frac{G}{D} \times 100
$$

The amount of food digested was calculated by subtracting the weight of feces from the weight of food ingested.

The efficiency of conversion of ingested food (ECI) The conversion of ingested food measurement indicates the overall efficiency of the insect to utilize the food for growth.

$$
E C I=\frac{G}{I} \times 100
$$


The following formula calculated approximate digestibility $(\mathrm{AD})$ and assimilation rate $(\mathrm{AR})$ :

$$
\begin{gathered}
\mathrm{AD}=\frac{\mathrm{I}-\mathrm{F}}{I} \times 100 \\
A R=C R \times A D
\end{gathered}
$$

Where;

$\Delta \mathrm{B}=$ Weight gained by an insect.

$\mathrm{BI}=$ Mean weight of insect during the feeding period

$\mathrm{T}=$ Duration of feeding period (days)

$\mathrm{I}=$ Weight of food ingested.

$\mathrm{B}=$ Average larval weight during the trial

$\mathrm{G}=$ Weight gained by the insect

$\mathrm{D}=$ Weight of food digested.

$\mathrm{F}=$ Weight of feces

\section{Statistical analysis}

Data normality was determined before the analysis. Digestibility and survival data were analysed using one-way analysis of variance (ANOVA) to check the effectiveness of botanicals using different solvents. Means were separated by using the Tukey HSD allpairwise comparison test. All the analyses were performed using Minitab 17.0 software.

\section{Results}

There was a significant effect of plant extracts using methanol $(\mathrm{F}=238.0, P<0.001)$, ethanol $(\mathrm{F}=24.9, P$ $<0.001)$ and acetone $(\mathrm{F}=140.0, P<0.001)$ as extraction solvents on consumption rate of $S$. litura larvae. The larvae's consumption rate was lower $(0.19-0.21 \mathrm{mg} / \mathrm{mg} /$ day $)$ when treated with $P$. hysterophorus at $50 \mathrm{mg}$ concentration compared to other treatments. Among the extraction solvents, methanolic extracts considerably affected the consumption rate in comparison to ethanol and acetone (Figure 1). Larval growth rate was significantly reduced by consumption of plant extracts using methanol $(\mathrm{F}=177.0, P<0.001)$ and ethanol $(\mathrm{F}=125.0, P<0.001)$ as extraction solvents. However, acetone-based leaf extracts yielded insignificant $(\mathrm{F}=2.76, P>0.05)$ results for both plants. Among plants, $P$. hysterophorus significantly affected the growth rate at $50 \mathrm{mg}$ concentration, wherein larval growth rate relative to control (+ve) treatment was reduced by $80.4 \%, 73.8 \%$, and $65.4 \%$ using methanol, ethanol, and acetone as solvents, respectively (Figure 1).
Plant extracts using methanol $(\mathrm{F}=66.1, P<0.001)$ and ethanol $(\mathrm{F}=57.6, P<0.001)$ had a significant effect on the efficiency of conversion of ingested food of $S$. litura larvae. However, using acetone $(\mathrm{F}=0.76$, $P>0.05)$ as extraction solvent, no significant difference was found among treatments. The efficiency of conversion of ingested food was reduced by $63.9 \%$ and $40.2 \%$, respectively, using methanol and ethanol extracts of $P$. hysterophorus at $50 \mathrm{mg}$ concentration (Figure 2). Similarly, a significant effect of methanolic $(\mathrm{F}=81.9, P<0.001)$ and ethanolic $(\mathrm{F}=$ 84.0, $P<0.001)$ plant extracts was found on the efficiency of conversion of digested food of $S$. litura larvae. An application of $P$. hysterophorus at $50 \mathrm{mg}$ concentration reduced the efficiency of conversion of digested food by about $68.4 \%$ with methanolic and by $47.6 \%$ with ethanol extract (Figure 2).

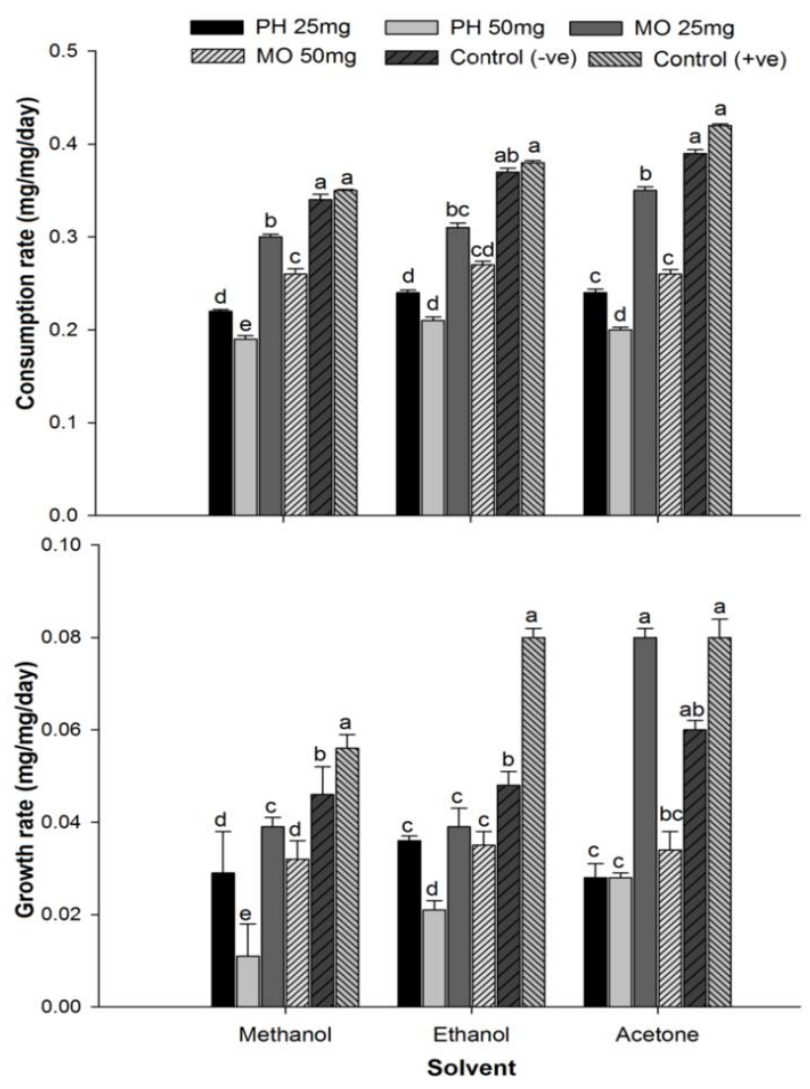

Figure-1: Effect (Mean \pm SE) of plant extracts with different extraction solvents on the consumption and growth rate of Spodoptera litura larvae, $\mathbf{P H}=$ Parthenium hysterophorus, $\mathrm{MO}=$ Moringa oleifera, Control (-ve) is respective solvent only, Control (+ve) is untreated, means sharing similar letters are not significantly different at $P=\mathbf{0 . 0 5}$ 


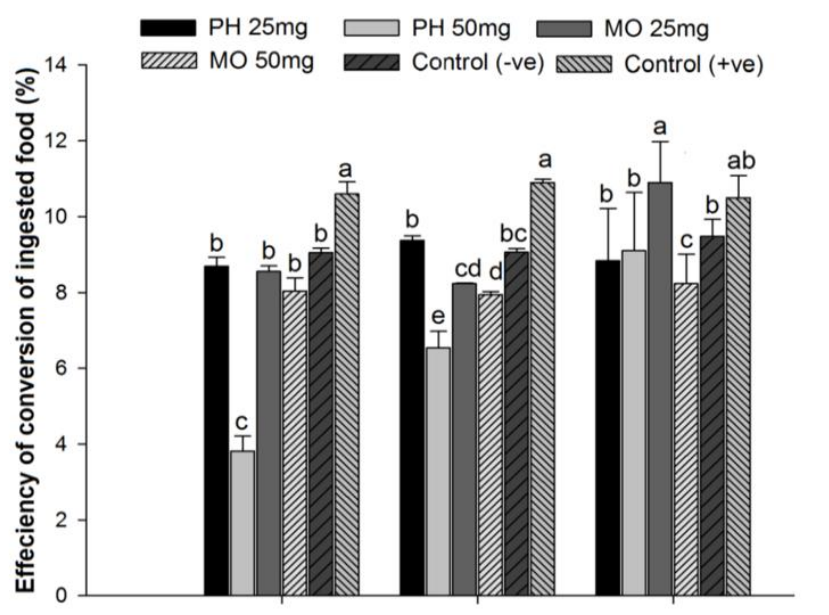

concentration compared with other plant extracts (Figure 3).

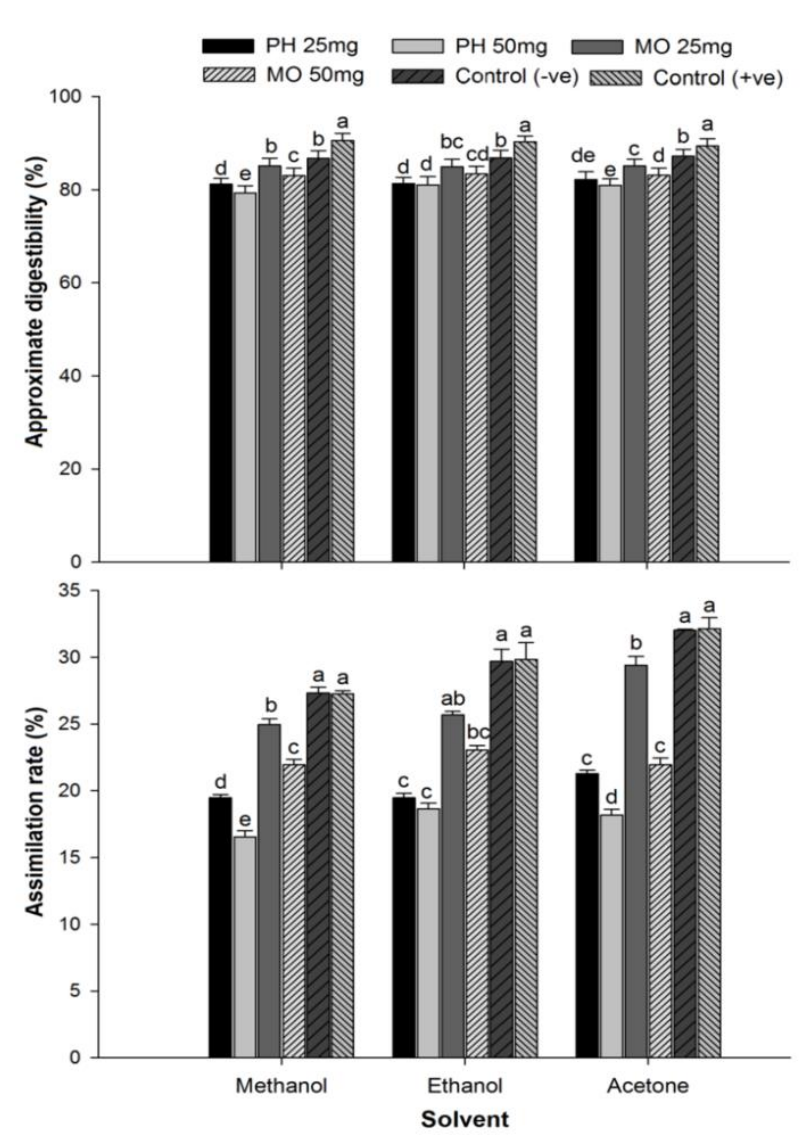

Figure-2: Effect (Mean \pm SE) of plant extracts with different extraction solvents on the efficiency of conversion of ingested and digested food of Spodoptera litura larvae, $\mathbf{P H}=$ Parthenium hysterophorus, MO = Moringa oleifera, Control (ve) is respective solvent only, Control (+ve) is untreated, means sharing similar letters are not significantly different at $\mathbf{P}=\mathbf{0 . 0 5}$

Plant extracts had significant (methanol, $\mathrm{F}=118.0, P$ $<0.001$; ethanol, $\mathrm{F}=36.7, P<0.00$ and acetone, $\mathrm{F}=$ 78.2, $P<0.001)$ effect on approximate digestibility of $S$. litura larvae. $P$. hysterophorus at $50 \mathrm{mg}$ concentration reduced digestibility by $9.0-13.0 \%$ approximately, relative to control (+ve) treatment (Figure 3). Furthermore, assimilation rate was also significantly affected after application of plant extracts with different solvents (methanol, $\mathrm{F}=134.0$, $P<0.001$; ethanol, $\mathrm{F}=21.8, P<0.001$ and acetone, $\mathrm{F}=141.0, P<0.001)$. Assimilation rate was higher when treated with $P$. hysterophorus at $50 \mathrm{mg}$

Figure-3: Effect (Mean \pm SE) of plant extracts with different extraction solvents on the approximate digestibility and assimilation rate of Spodoptera litura larvae, $\mathbf{P H}=$ Parthenium hysterophorus, MO = Moringa oleifera, Control (ve) is respective solvent only, Control (+ve) is untreated, means sharing similar letters are not significantly different at $\mathbf{P}=\mathbf{0 . 0 5}$

The survival rate of larvae was higher in control treatments compared to those treated with botanicals. With time, the survival rate decreased to $6.0-14.0 \%$ in $P$. hysterophorus using three different solvents after $4^{\text {th }}$ day of exposure. In M. oleifera, the larval survival rate was $20.0-26.0 \%$ at $50 \mathrm{mg}$ concentration and $26.0-46.0 \%$ at $25 \mathrm{mg}$ concentration after the $4^{\text {th }}$ day of exposure (Figure 4). 


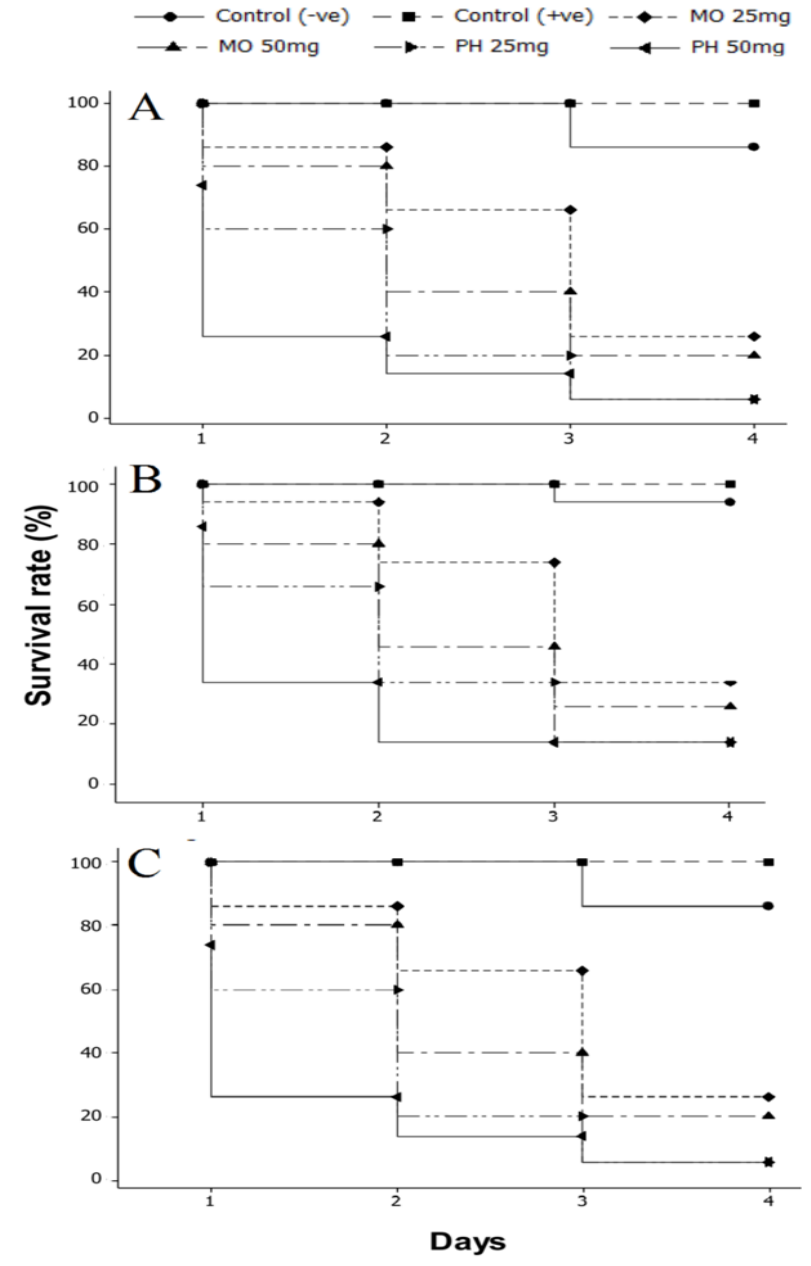

Figure-4: Effect (Mean \pm SE) of plant extracts with different extraction solvent; methanol (A), ethanol (B) and acetone $(C)$ on the survival rate of Spodoptera litura larvae, $\mathbf{P H}=$ Parthenium hysterophorus, MO = Moringa oleifera, Control (ve) is respective solvent only, Control (+ve) is untreated.

\section{Discussion}

Botanical insecticides are considered a potential method to manage diverse insect pests (Pavela, 2014). Insects feeding upon plants' toxic materials suffer a reduction in their growth and development, resulting in insect mortality (Shaheen and Khaliq, 2005). In this study, $P$. hysterophorus showed adverse effects on larval development and the growth rate of $S$. litura. This was most significant at $50 \mathrm{mg}$ concentration, wherein larval growth rate relative to control (+ve) treatment was reduced by $65-85 \%$ using different extraction solvents. Different leaf extracts of
M. oliefera were also tested for their insecticidal properties, but their effect on $S$. litura larvae was much less than $P$. hysterophorus. Previously, $M$. oliefera has been reported as an effective substance in controlling the field and stored grain insect pests (Prabhu et al., 2011). However, the current study yielded moderate results on its efficacy in comparison to $P$. hysterophorus. $P$. hysterophorus is reported to be a very effective substance to control the mosquito population on account of its biological activities (Kumar et al., 2012). All parts of this weed, including trichomes and pollen, contain toxins known as sesquiterpene lactones that show promising insecticidal activity (Datta and Saxena, 2001). Sesquiterpene lactones consist of cytotoxic, antifeedant, phytotoxic, antimicrobial, and insecticidal properties (Rodriguez et al., 1976), but the major compound of these toxins is parthenin and other phenolics (Oudhia, 2001).

In the present case, the methanol extract of $P$. hysterophorus prepared from the aerial parts of the plant proved to be most effective against the growth rate of $S$. litura. The consumption rate of larvae was reduced when they fed on P. hysterophorus-treated leaves. The larvae's food uptake capacity was affected more while feeding on $P$. hysterophorustreated leaves, which led to the growth retardation/suspension of $S$. litura larvae. Similarly, the reduced efficiency of converting ingested food indicated the disruption of digestibility, showing long-term effects on larval growth and development. We believe that there was a disturbance in the physiology of $S$. litura, which rendered them unable to digest the available food. The adverse effects of $P$. hysterophorus extracts on the conversion efficiency of ingested food of S. litura larvae could be attributed to either having the ability to inhibit the conversion of nutrients for growth or reduction of larval ability to absorb and digest the nutrients from the food treated with pesticidal plant extracts. Reduction in the ability of insects to convert food into biomass or reduction in food intake ultimately extends the larval developmental period, which occurs most probably due to the effect of botanicals on the hormones like ecdysteroids and juvenile (Morgan, 2009). Previously, the insecticidal and acaricidal activities of $P$. hysterophorus extracts have been shown to affect survival rate, inhibit growth, and act as antifeedant against S. littoralis larvae (Pavela et al., 2010). Furthermore, the $P$. hysterophorus extracts have also shown an acaricidal effect on Tetranychus urticae 


\section{Muhammad Irfan Ullah et al.}

(Trombidiformes; Tetranychidae) by causing greater mortality mites (Erdogan et al., 2012). In the current study, plant extracts showed considerable effects on the digestibility parameters of $S$. litura that caused a significant reduction of food intake (CR) and growth rate (GR) of larvae compared to control treatment. Many studies have reported the antifeedant effect of different plant extracts (Mogg et al., 2008; Pavela, 2009, 2010) and different secondary metabolites, such as alkaloids (Pavela, 2010), tannins (Lingathurai et al., 2011), terpenes (Kumar et al., 2013) and phenolics (Pavela, 2009).

Approximate digestibility of S. litura was indicated by the reduced rate of ingested food, which was affected more when larvae fed on $P$. hysterophorustreated leaves. Because of the detrimental effects of $P$. hysterophorus extracts with methanol as a solvent on the feeding behavior of $S$. litura larvae, the survival rate was markedly reduced in comparison to other treatments. Overall, the growth rate of larvae, calculated as growth rate and total weight gained, was inhibited by $P$. hysterophorus, but the effect depended on the concentration and the type of extraction solvent. The higher concentration $(50 \mathrm{mg})$ of $P$. hysterophorus had a greater effect on the digestibility indices of $S$. litura compared to other treatments. The diluted extracts might have enhanced the metabolism, whereas the more concentrated extract might have slowed down the metabolic rate (Bashir et al., 2013).

The $P$. hysterophorus extract using methanol as an extraction solvent was more toxic to $S$. litura larvae than another extraction solvent (ethanol and acetone). The solvent's polarity is also an essential factor in toxicology studies (Khan et al., 2015). However, variations in the larval growth and development, and survival could be attributable to $P$. hysterophorus extract's dissolving nature in different solvents (Rizvi et al., 2012; Koubala et al., 2013). The active ingredients in plant extracts in different extraction solvents may have different dissolving nature and may show the synergistic effect with a respective solvent against a particular pest (Oyedokun et al., 2011). These explanations can be efficient in terms of the compound's polarity being extracted in each solvent. However, methanol is better in dissolving organic compounds than other solvents and shows higher bioactivity against pests as it has more toxic compounds (Abdulhay et al., 2012). In fact, as observed in the current study, ethanol and acetone extracts showed lower toxicity towards different indices of S. litura. Variation in the toxicity of plant extracts obtained using different polarity solvents was also observed in many previous studies (Boussaada et al., 2008; Germinara et al., 2011). However, chemical analysis of methanol extract is needed to support this hypothesis. Furthermore, the knowledge of the composition of extraction solvent and its dissolution abilities and binding with phytochemicals should be focused on closer insight into plant-based insecticides' development.

\section{Conclusion}

Botanicals had wide application in the past, but synthetic pesticides gradually replaced these. However, synthetic pesticides' detrimental effects on the environment and human health have called for reemployment of plant-derived products to control pest infestation of important food commodities. The effectiveness of plant-based toxins becomes more prominent when insects develop resistance against synthetic pesticides. The current study reported the efficacy of $50 \mathrm{mg}$ methanolic extract of $P$. hysterophorus as an insect growth regulator and antifeedant against the common pest, S. litura. Ecofriendly botanical preparations like those used in this study, prepared from local flora, can be easily available to the farmers advocating use as ecofriendly alternatives to synthetic pesticides.

\section{Acknowledgment}

The authors sincerely thank the Department of Chemistry, the University of Sargodha, to provide workspace and lab facilities.

Disclaimer: None.

Conflict of Interest: None.

Source of Funding: None.

\section{References}

Abdulhay B, Bourouga B and Dessain C, 2012. Thermal contact resistance estimation: influence of the pressure contact and the coating layer during a hot forming process. Int. J. Mater. Form. 5: 183-197. https://doi.org/10.1007/s12289-0111039-6

Ahmad M, Arif MI and Ahmad M, 2007. Occurrence of insecticide resistance in field populations of 
Spodoptera litura (Lepidoptera: Noctuidae) in Pakistan. Crop Protect. 26: 809-817. https://doi.org/10.1016/j.cropro.2006.07.006

Ahmad M, Ghaffar A and Rafiq M, 2013. Host plants of leaf worm, Spodoptera litura (Fabricius) (Lepidoptera: Noctuidae) in Pakistan. Asian J. Agric. Biol. 1: 23-28.

Anita S, Sujatha P and Prabhudas P, 2012. Efficacy of pulverised leaves of Annona squamosa (L.), Moringa oleifera (Lam.) and Eucalyptus globulus (Labill.) against the stored grain pest, Tribolium castaneum (Herbst.). Recent Res. Sci. Technol. 4: 19-23.

Anwar F, Latif S, Ashraf M and Gilani AH, 2007. Moringa oleifera: a food plant with multiple medicinal uses. Phytother. Res. 21(1): 17-25. http://doi:10.1002/ptr.2023

Bandonien D, Pukalskas A, Venskutonis $\mathrm{P}$ and Gruzdien D, 2000. Preliminary screening of antioxidant activity of some plant extracts in rapeseed oil. Food Res. Int. 33(9): 785-791. https://doi.org/10.1016/S0963-9969(00)00084-3

Bashir M, Gogi MD, Ashfaq M, Afzal DM, Khan MA and Ihsan M, 2013. The efficacy of crude aqueous extracts of some plants as grain protectants against the stored grain mite, Rhizoglyphus tritici. Turk. J. Agric. For. 37(5): 585-594. http://doi:10.3906/tar1205-25

Baskar K, Kingsley S, Vendan SE, Paulraj MG, Duraipandiyan V and Ignacimuthu S, 2009. Antifeedant larvicidal and pupicidal activities of Atalantia monphylla (L.) Correa against Helicoverpa armigera (Hubner) Lepidoptera:Noctuidae) Chemosphere. 75: 345349.

Baskar K, Maheshwaran R, Kingsley S and Ignacimuthu S, 2010. Bioefficacy of Couroupita guianensis (Aubl) against Helicoverpa armigera (Hub.) (Lepidoptera:Noctuidae) larvae. Span J. Agric. Res. 8: 135-141.

Boussaada O, Kamel MBH, Ammar S, Haouas D, Mighri Z and Helal AN, 2008. Insecticidal activity of some Asteraceae plant extracts against Tribolium confusum. Bull. Insect. 61(2): 283-289.

Coelho JS, Santos ND, Napoleão TH, Gomes FS, Ferreira RS and Zingali RB, 2009. Effect of Moringa oleifera lectin on development and mortality of Aedes aegypti larvae. Chemosphere. 77(7): 934-938. http://doi:10.1016/j.chemosphere.2009.08.022

Datta S and Saxena DB, 2001. Pesticidal properties of parthenin (from Parthenium hysterophorus) and related compounds. Pest Manage. Sci. 57(1): 95$101 . \quad$ http://doi:10.1002/15264998(200101)57:1<95::AID-PS248>3.0.CO;2-J

Dougoud J, Toepfer S, Bateman M and Jenner WH, 2019. Efficacy of homemade botanical insecticides based on traditional knowledge. A review. Agron. Sustain. Dev. 39: 37. https://doi.org/10.1007/s13593-019-0583-1

de Lima Santos ND, da Silva Paixão K, Napoleão TH, Trindade PB, Pinto MR and Coelho LCBB, 2014. Evaluation of Moringa oleifera seed lectin in traps for the capture of Aedes aegypti eggs and adults under semi-field conditions. Parasitol. Res. 113(5): 1837-1842. https://doi.org/10.1007/s00436-014-3830-z

de Oliveira CFR, Luz LA, Paiva PMG, Coelho LCBB, Marangoni S and Macedo MLR, 2011. Evaluation of seed coagulant Moringa oleifera lectin (cMoL) as a bioinsecticidal tool with potential for the control of insects. Process Biochem. 46(2): 498504. https://doi.org/10.1016/j.procbio.2010.09.025

EPPO, 2014. PQR database. Paris, France: European and Mediterranean Plant Protection Organization. http://www.eppo.int/DATABASES/pqr/pqr.htm Accessed on 04.03.2020

Erdogan P, Yildirim A and Sever B, 2012. Investigations on the effects of five different plant extracts on the two-spotted mite Tetranychus urticae Koch (Arachnida: Tetranychidae). J. Entomol.

23:1-5. http://dx.doi.org/10.1155/2012/125284

Feng X, Jiang H, Zhang Y, He W and Zhang L, 2012. Insecticidal activities of ethanol extracts from thirty Chinese medicinal plants against Spodoptera exigua (Lepidoptera: Noctuidae). J. Med. Plants Res. 6(7): 1263-1267.

Germinara GS, Frontera AM, de Cristofaro A and Rotundo G, 2011. Insecticidal activity of different extracts from Scrophularia canina L. against Culex pipiens molestus Forskal (diptera, culicidae). J. Environ. Sci. Health B. 46: 473-479. http://doi:10.1080/03601234.2011.583858

Gören N, Tahtasakal E, Krawiec M and Watson WH, 1996. A guaianolide from Tanacetum argenteum subsp. flabellifolium. Phytochem. 42: 757-760. https://doi.org/10.1016/0031-9422(95)00973-6

Isman MB, 2006. Botanical insecticides, deterrents, and repellents in modern agriculture and an increasingly regulated world. Ann. Rev. Entomol. 51:

45-66. 
https://doi.org/10.1146/annurev.ento.51.110104.15 1146

Isman MB, Miresmailli S and Machial C, 2011. Commercial opportunities for pesticides based on plant essential oils in agriculture, industry and consumer products. Phytochem. Rev. 10: $197-$ 204. https://doi.org/10.1007/s11101-010-9170-4

Khan RR, Ahmed S and Arshad M, 2015. Laboratory assessment of repellence and insecticide efficacy of some plant extracts against adults of red pumpkin beetle (Aulacophora foveicollis Lucas). Pak. J. Life Social Sci. 13(1): 49-57.

Khan RR, Ahmed S and Nisar S, 2011. Mortality responses of Spodoptera litura (Fab.)(Lepidoptera: Noctuidae) against some conventional and new chemistry insecticides under laboratory conditions. Pak. Entomol. 33(2): 147-150.

Khan RR, Ali RA, Ali A, Arshad M, Majeed S, Ahmed S and Khan SA, 2018. Compatibility of entomopathogenic nematodes (Nematoda: Rhabditida) and the biocide, spinosad for mitigation of the armyworm, Spodoptera litura (F.)(Lepidoptera: Noctuidae). Egypt. J. Biol. Pest Cont. 28(1): 58. https://doi.org/10.1186/s41938018-0063-y

Khatun S, Khan MMH, Ashraduzzaman M, Pervin F, Bari L and Absar N, 2009. Antibacterial activity and cytotoxicity of three lectins purified from drumstick (Moringa oleifera Lam.) leaves. J. BioSci. 17: 89-94.

Koubala BB, Kansci G, Garnier C, Thibault JF and Ralet MC, 2013. Physicochemical properties of dietary fibres prepared from ambarella (Spondias cytherea) and mango (Mangifera indica) peels. Food Bioprocess Technol. 6(2): 591-597. https://doi.org/10.1007/s11947-011-0660-1

Kumar S, Mishra A and Pandey AK, 2013. Antioxidant mediated protective effect of Parthenium hysterophorus against oxidative damage using in vitro models. BMC Complement. Altern. $\quad$ Med. 13(1): 120. https://doi.org/10.1186/1472-6882-13-120

Kumar S, Nair G, Singh AP, Batra S, Wahab N and Warikoo R, 2012. Evaluation of the larvicidal efficiency of stem, roots and leaves of the weed, Parthenium hysterophorus (Family: Asteraceae) against Aedes aegypti L. Asian Pac. J. Trop. Dis. 2(5): 395-400. https://doi.org/10.1016/S22221808(12)60086-3

Lingathurai S, Vendan SE, Paulraj MG and Ignacimuthu S, 2011. Antifeedant and larvicidal activities of Acalypha fruticosa Forssk.(Euphorbiaceae) against Plutella xylostella L.(Lepidoptera: Yponomeutidae) larvae. J. King Saud University-Sci. 23(1): 11-16. https://doi.org/10.1016/j.jksus.2010.05.012

Liu D, Jia ZQ, Peng YC, Sheng CW, Tang T, Xu L, Han ZJ and Zhao CQ, 2018. Toxicity and sublethal effects of fluralaner on Spodoptera litura Fabricius (Lepidoptera: Noctuidae). Pesticide Biochem. Physiol. 152: 8-16. https://doi.org/10.1016/j.pestbp.2018.08.004

Mkindi A, Mpumi N, Tembo Y, Stevenson PC, Ndakidemi PA, Mtei K, Machunda R and Belmain SR, 2017. Invasive weeds with pesticidal properties as potential new crops. Ind. Crops Prod. 110: 113-122.

Mogg C, Petit P, Cappuccino N, Durst T, McKague C, Foster M, Yack JE, Arnason JT and Smith ML, 2008. Tests of the antibiotic properties of the invasive vine Vincetoxicum rossicum against bacteria, fungi and insects. Biochem. Syst. Ecol. 36(5-6): 383-391. https://doi.org/10.1016/j.bse.2008.01.001

Monobrullah M and Shankar U, 2008. Sub-lethal effects of Splt MNPV infection on developmental stages of Spodoptera litura (Lepidoptera: Noctuidae). Biocontrol Sci. Technol. 18(4): 431437. https://doi.org/10.1080/09583150801994137

Morgan ED, 2009. Azadirachtin, a scientific gold mine. Bioorganic Med. Chem. 17: 4096-4105.

Nerio LS, Olivero-Verbel J and Stashenko E, 2010. Repellent activity of essential oils. Bioresource Technol. 101: 372-378. https://doi.org/10.1016/j.biortech.2009.07.048

Oudhia P, 2001. Parthenium hysterophorus: Traditional Medicinal Uses. Society for Parthenium Management (SOPAM).

Oyedokun A, Anikwe J, Okelana F, Mokwunye I and Azeez O, 2011. Pesticidal efficacy of three tropical herbal plants' leaf extracts against Macrotermes bellicosus, an emerging pest of cocoa, Theobroma cacao L. J. Biopest. 4(2): 131.

Pavela R and Benelli G, 2016. Essential oils as ecofriendly biopesticides? Challenges and constraints. Trends Plant Sci. 21: 1000-1007. https://doi.org/10.1016/j.tplants.2016.10.005

Pavela R, 2009. Larvicidal effects of some EuroAsiatic plants against Culex quinquefasciatus Say larvae (Diptera: Culicidae). Parasitol. Res. 105(3): 887. https://doi.org/10.1007/s00436-009-1511-0

Pavela R, 2010. Antifeedant activity of plant extracts 
Muhammad Irfan Ullah et al.

on Leptinotarsa decemlineata Say and Spodoptera littoralis Bois larvae. Ind. Crops Prod. 32(3): 213219. https://doi.org/10.1016/j.indcrop.2010.04.010

Pavela R, 2014. Acute, synergistic and antagonistic effects of some aromatic compounds on the Spodoptera littoralis Boisd. (Lep., Noctuidae) larvae. Ind. Crops Prod. 60: 247-258. https://doi.org/10.1016/j.indcrop.2014.06.030

Pavela R, Sajfrtová M, Sovová H, Bárnet $M$ and Karban J, 2010. The insecticidal activity of Tanacetum parthenium (L.) Schultz Bip. extracts obtained by supercritical fluid extraction and hydrodistillation. Ind. Crops Prod. 31(3): 449-454. https://doi.org/10.1016/j.indcrop.2010.01.003

Prabhu K, Murugan K, Nareshkumar A, Ramasubramanian $\mathrm{N}$ and Bragadeeswaran $\mathrm{S}$, 2011. Larvicidal and repellent potential of Moringa oleifera against malarial vector, Anopheles stephensi Liston (Diptera: Culicidae). Asian Pac. J. Trop. Biomed. 1(2): 124-129. https://doi.org/10.1016/S2221-1691(11)60009-9

Rajendran S and Sriranjini V, 2008. Plant products as fumigants for stored-product insect control. J. Stored Product Res. 44: 126-135. https://doi.org/10.1016/j.jspr.2007.08.003

Rizvi AH, Khan M, Saxena G and Naqvi A, 2012. A comparative study on the chemical composition of oil obtained from whole seeds and crushed seeds of Nigella sativa L. from India. J. Biol. Chem. Res. 29(1): 44-51.

Rodriguez E, Towers G and Mitchell J, 1976. Biological activities of sesquiterpene lactones. Phytochem. 15: 1573-1580. https://doi.org/10.1016/S0031-9422(00)97430-2

Santos AF, Luz LA, Argolo AC, Teixeira JA, Paiva
PM and Coelho LCBB, 2009. Isolation of a seed coagulant Moringa oleifera lectin. Process Biochem. 44(4): 504-508. https://doi.org/10.1016/j.procbio.2009.01.002

Shaheen FA and Khaliq A, 2005. Management of Pulse Beetle, Callosobruchus chinensis L. (Coleoptera: Bruchidae) in stored Chickpea using ashes, red soil powder and turpentine oil. Pak. Entomol. 27(2): 19-24.

Sharma R and Joshi V, 1977. Allomonic principles in Parthenium hysterophorus: potential as insect control agents and role in the weed's resistance to serious insect depredation. the biological activity of parthenin on insects. Biovig. 2013: 225-231.

Sorour M, Khamiss O, El-Wahab A, El-Sheikh M and Abul-Ela S, 2011. An economically modified semi-synthetic diet for mass rearing the Egyptian cotton leaf worm Spodoptera littoralis. Acad. J. Entomol. 4(3): 118-123.

Waldbauer G, 1968. The consumption and utilization of food by insects. Adv in Insect Phys. 5: 229288. https://doi.org/10.1016/S00652806(08)60230-1

\section{Contribution of Authors}

Ullah MI, Majeed S \& Arshad M: Conceived idea, designed research methodology, data analysis, literature review and manuscript write up Ali S, Mehmood N, Altaf N \& Afzal M: Helped in designing research methodology, data collection and data interpretation Abdullah A, Luqman M \& Farooq U: Helped in designing research methodology, data collection and article write up 